\title{
Left Posteromedial Apical Peripheral Zone of Prostate
}

National Cancer Institute

\section{Source}

National Cancer Institute. Left Posteromedial Apical Peripheral Zone of Prostate. NCI

Thesaurus. Code C128577.

The region of the prostate that is located on the anatomical left side of the posteromedial portion of the apical division of the peripheral zone. 